\title{
ACCURACY, INTEGRITY AND SECURITY IN COMPUTERIZED VOTE-TALLYING
}

\author{
The following excerpts have been gleaned from a 130-page report of \\ potential inaccuracies and fraud in computerized voting systems. Recent \\ difficulties in automated vote-tallying, including specific legal cases, are \\ detailed along with a summary of conclusions and recommendations.
}

ROY G. SALTMAN

There are several examples of difficulties in the use of computerized vote-tallying, that occurred in the years 1980-1986. Two such cases took place in Carrull County, Maryland and Stark County, Ohio. It should be noted that the following descriptions are not intended to be the definitive versions of what occurred. No absolute proof can be offered that the events occurred exactly as described. However, reported data have been supplied by named sources on the scene, and exact quotations by participants and observers are given when appropriate.

Carroll County, Maryland: November, 1984

Carroll is a county of about 100,000 population located about 30 miles northwest of the city of Baltimore. On November 8 , two days after the Tuesday, November 6 , 1984 general election, and in accordance with the rules of the Maryland State Administrative Board of Election Laws (SABEL), voted punch card ballots from two districts of Carroll County were taken to a neighboring county, Frederick, to be rerun on an independentlymanaged system. (Similarly, ballots from Frederick County were taken to Caroll to be rerun.) This rerun is necessary under Maryland regulations to verify the original results before certification.

(C) 1988 ACM 0001-0782/88/1000-1184\$1.50
It was clear from these reruns that one of the computers used was in error in determining the outcome of a contest between Wayne Cogswell and in.cumbent T. Edward Lippy, for Carroll County School Board. Manual counts of the votes on ballots from both Frederick and Carroll counties showed that the Carroll County computer was the one that was incorrect. The initial but unofficial count, made public on the evening of the election, had indicated incorrectly thet Cogswell was the winner.

An investigation undertaken the next day (November 9) by Craig Jester, a county computer program contractor, demonstrated that a wrong utility computer program for reading the ballot cards had been used. After the correct utility program was installed, the results coincided with those obtained manually and. with the Frederick County computer. The utility program, named COLBIN, had been previously written by Jester under contract to the county and had been successfully used in the May, 1984, primary election.

The purpose of the COLBIN utility program was to read the voted ballot cards in the "column hinary" format used for voting, rather than in a simpler format. At the request of Carroll County DP personnel to reduce the price, Computer Election Systems, the vendor of the vote-tallying system, had supplied the system with an elementary utility program that could read cards only in the simpler format. With this format, ballot 
cards would be required to have a maximum of one punch per column, not an acceptable situation for the Carroll County ballot. Carroll County contracted locally (with Pelorus, whose president was Craig Jester) for the COLBIN utility program.

On Saturday, November 10, the count was rerun (using the vote-tallying system including the COLBIN program). Members of the county Board of Elections and the County attorney were in attendance. The count indicated that Lippy was the winner. On Wednesday, November 14, eight days after the election, the Board of Elections certified the results. Lippy was named the winner.

The cause of the error was reported in the Carroll Sun on Nov. 18, 1984 in an article by Steve Kelly [6]. A more complete explanation was provided in a letter, dated Nov. 26, 1984, from Thomas J. Van de Bussche, administrator of the Data Processing Center of Carroll County, to Dr. Thomas Lewis, president of the Carroll County Election Board [9]. Mr. Van de Bussche's letter was included in a report submitted by Dr. Lewis on December 5, 1984 to Mrs. Marie Garber, administrator of SABEL [7].

Mr. Van de Bussche admitted that, in testing an improved vote-tallying system provided by Computer Election Systems, he had inadvertently replaced the production version with a test version that did not include the COLBIN utility program. The logic and accuracy test of the vote-tallying system on Oct. 25, 1984, performed prior to the election in accordance with Maryland regulations, produced results consistent with the test ballots used. None of the test ballots had more than one punch in any column. Therefore, the test ballots did not reveal the error.

In the general election of November 6, 1984, the contest for the school board seat in question was listed in the same punch card columns as a home rule issue. The two contests were listed on different ballot pages of the "votomatic" ballot holder. The combination of votes for a school board candidate and a particular home rule position in the same column created a punch configuration that was not recognized as valid by the elementary utility program. As a result, some valid votes were not recorded in both the school board and home rule issue contests. Most of the votes not recorded (about 13,000) were for Lippy, because many Lippy voters chose the home rule position listed in the same card column. Votes not recorded on the home rule issue did not affect the ultimate outcome for that question. If the COLBIN utility program had been used, all votes on the contests would have been recognized as valid.

In summary, the incorrect announcement of the result of the school board contest on election night was due to mistakes by the Data Processing Center of Carroll County in using the wrong utility program and in using a perfunctory logic test that did not disclose the problem before the election. No factual evidence is available that contradicts the documentation submitted to Mrs. Garber by Dr. Lewis and Mr. Van de Bussche.
The incorrect announcement was not due to any error in the vote-tallying computer system supplied by the primary vendor, Computer Election Systems, nor any activity undertaken by its representatives. Nevertheless, on July 29, 1985, the New York Times, in referring to this particular situation, reported that "The vote counting program that has been challenged in ... Maryland was developed by Computer Election Systems of Berkeley, Calif." [2].

The error was discovered after the election but before certification because of a Maryland regulation that required recounting on an independently managed system. This specific regulation was based on a recommendation that "further confidence in the machinecounted results can be achieved if mandatory machine recounting of a percentage of the precincts for each race is carried out on a different, independently managed computing system than that used to produce the official count" [8].

On June 11, 1985, another recount of the school board race in question was carried out, using the Carroll County computer, again including the COLBIN program. This recount was undertaken at the request of the State court in which Mr. Cogswell, the defeated candidate, had filed a suit asking that the results of the election be re-examined. The recount verified the correctness of the election results certified on Nov. 14, 1984, although Mr. Van de Bussche has indicated that the recount results did not exactly match the count reported in the certification.

Mr. Van de Bussche has stated that the recount, carried out with all sides in attendance, was hurried and less than precise in that, with the permission of the court, card reader "checks" were ignored in the ballotreading process. Usually a card reader "check," indicative of a reading failure, would result in a decision to re-read the entire precinct of voted ballot cards. Instead, the card or cards causing the "check" remained unread and the reading process continued. The failure to re-read an entire precinct upon occurrence of a read "check" resulted in a small but random reduction of votes to both candidates, according to $\mathrm{Mr}$. Van de Bussche. The differences were not significant enough to raise reasonable doubt as to the correctness of the certified results.

According to a July 11, 1985 story by Chris Guy in the Carroll County Times referring to the court-ordered recount, “. .. defeated candidate Wayne Cogswell had verification that use of an incorrect computer program caused a nearly 13,000 -vote mistake in the unofficial totals released elestion night" [4].

\section{Stark County, Ohio: May, 1986}

The following description is adapted from the account given in the July 21, 1986 issue of Election Administration Reports [1], Richard G. Smolka, editor, with permission of the publisher.

Stark is a county of about 400,000 population located about 60 miles south-southeast of Cleveland. An un- 
precedented court-ordered "audit" (hand recount) of a Stark County computer recount in a county commissioner's primary contest again named as winner the candidate who had apparently won in the official results of the May 6, 1986 primary but lost in the computer recount. The audit revealed a computer program error that permitted over 100 invalid punchcard ballots to be counted in the recount.

At the end of the election-night count, Robert A. Capestrain held a 26-vote lead in the three-person contest to be Democratic nominee for county commissioner. A recount by computer on May 27 (held because of the closeness of the original tally) put Patty Miller ahead by 5 votes. For the computer recount, the computer program used to obtain the original results was not used. Instead, a special computer program was written, in order to count only the disputed contest and not the other contests on the ballot. The mystery, however, was why 165 additional votes had been tallied in the recount although the number of ballots read by the computer was the same.

The following table provides the votes for the three candidates in the computer tally of the primary, the computer recount, and the hand counted audit: vote count would be complete and accurate. Most importantly, they all agreed that the audit would constitute a final resolution of the vote count dispute. Judge Harold E. DeHoff of the Stark County Court of Common Plcas included a provision in the agreement that all parties would waive any rights of appeal.

The audit included a manual count and a computer count. A large number of 2-person teams were assigned to manually count the ballots under specific rules. The court order also provided guidelines on removal of hanging chad and specified that only the two master commissioners, appointed by the court, could remove a suspected chad or hanging chad.

Before the start of the audit, Ohio Director of Elections Dorothy Woldorf and area manager Robert Braun of the vote-counting system vendor gave the counting teams both written and verbal instructions on procedures to be followed. The manual recount began at 9:00 a.m. and continued until completion at about 7:45 p.m.

After the first several precincts were manually counted, it became evident that the audit was producing totals more closely matching the original count rather than the recount. By 11:00 a.m., the recount program error had been uncovered. The error was due

Votes Counted for Stark County Commissioner

Democratic Primary Election, 1986

\begin{tabular}{|c|c|c|c|c|c|}
\hline Candidates & Phingry & $\begin{array}{l}\text { Pecounh } \\
\text { hay } 7\end{array}$ & Change & 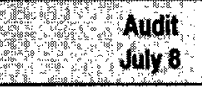 & Change \\
\hline Robert A. Capestrain & 12,967 & 13,018 & +51 & 12,980 & -38 \\
\hline Donald E. Casar & 7,987 & 8,019 & +32 & 7,989 & -30 \\
\hline Patty Miller & 12,941 & 13,023 & +82 & 12,952 & -71 \\
\hline TÓTALS & $\overline{33,895}$ & $\overline{34,060}$ & $\overline{+165}$ & $\overline{33,921}$ & $\overline{-139}$ \\
\hline
\end{tabular}

The 165 additional votes in the recount were randomly distributed throughout the 481 precincts. Most precincts had no changes, and most of those with changes had a one-vote increase. All candidates gained votes. The names of the candidates were rotated by precinct in the ballot booklets in positions 98-100-102, and the extra votes were distributed among these numbers on the ballot cards. Each of the three positions received approxinately the same number of additional votes.

Initially, there seemed to be no satisfactory explanation for the additional votes. Hanging chad (bits of paper remaining after holes are punched) was suspected as a possible cause. Fraud was much less likely because it would have required access to ballots from all affected precincts, working knowledge of the ballot rotations, plus sufficient time to locate and punch ballots which had not been voted for county commissioner.

Following the computer recount that indicated a reversal of the initial count, candidate Capestrain filed suit challenging the recount. Because of the unusual nature of the recount result and rumors of fraud, the candidates, attorneys, election board, and court agreed to audit procedures that would resolve any identifiable problems with hanging chad as well as ensure that the to the failure of the recount program to distinguish between Democratic, Republican, and unaffiliated ballots.

In the May 8 primary, voters were given Democratic, Republican, or unaffiliated ballots, depending on their party registration. The logic in the computer program and associated header cards that were used to tally the primary ballots was able to distinguish among the different types of ballots, even though all the ballots were tallied on the same computer equipment.

In the recount, all the ballots were again tallied together on the same equipment, but the logic of the recount program could not distinguish among the different ballot types. It was apparently believed by the author of the recount program that the assignment of unique ballot positions to each contest and candidate was sufficient to separate the ballots. However, some Republican and unaffiliated voters had "voted" (i.e., punched out chad) in a ballot position assigned to a candidate in the Democratic county commissioner contest. These ballots were not counted in the Democratic primary tally, but they were counted by mistake in the computer recount.

In the audit on July 8 , the ballots were first separated by party before being given to the two-person teams. The separation was easily accomplished because the 
ballot types were distinguishable by color. Consequently, in the manual recount, "votes" by Republican and unaffiliated voters were not tallied.

During the audit, the master commissioners completed removal of chad on 28 ballot cards. Nine of these were identified as hanging chad, and the others were termed "bulging chad." One commissioner said that it was obvious that the voter had detached the chad, but that it had been pressed back into position, probably when the cards were stacked. The removal of the chad by the commissioners had no effect on the outcome, but did increase the vote by a net of 26 over the original count. trails that document election results, as well as general practices to assure accuracy, integrity, and security, can be considerably improved.

\section{Government Responsibilities}

The recommendations that respond to these problems are directed to state and local government election officials. Elections for state and federal offices are conducted by local government (generally county, township, and city) administrators. In about one-third of all counties, including over one-half of all registered voters, voting is carried out using computerized equipment. The local administrators require the necessary

\section{"The computer program that was used to count more than one-third of the votes cast in the Presidential election last year is very vulnerable to manipulation and fraud, according to expert witnesses in court actions challenging local and Congressional elections in three states..."}

\section{SUMMARY OF CONCLUSIONS AND RECOMMENDATIONS}

This report has been prepared with funding provided by the John and Mary R. Markle Foundation of New York City. The Markle Foundation requested that the National Bureau of Standards (NBS) undertake this study because of public concern about the potential for inaccuracy or fraud in computerized vote-tallying. NBS was approached because of its experience with the subject matter as the result of a previous project undertaken by the author for the U.S. General Accounting Office [8].

Concern had been heightened by a series of articles published in the summer of 1985 in the New York Times. The articles cited statements by two computer experts reporting that a computer program widely used for vote-tallying was vulnerable to tampering. Several elections were identified in which losing candidates claimed that it would be possible to fraudulently alter the computer programs that were used in their contests.

In preparation for this report, a review of recent public statements and documents was undertaken that indicated concern about computerized vote-tallying. The review showed that the problems could be categorized as follows: there is difficulty in verifying results; there is the possibility of undiscoverable frauds; and election administrators lack the necessary knowledge and resources.

There is a continuing problem of public confidence. While proof of actual computer program manipulation appears to be lacking, documentation conclusively demonstrating otherwise is generally insufficient, due to the manner in which many computerized elections are conducted. It has been clearly shown that audit resources and expertise to efficiently and effectively carry out their responsibilities.

These responsibilities generally include procurement of vote-tallying systems and supporting services. An effective procurement must include the development of specifications so that accuracy, integrity, and security will be assured. The local administrators also have the responsibility for implementing the necessary management control systems to enable the public to have confidence in the results produced.

Election officials require a source of neutral expertise for the receipt of new technical and administrative information. The establishment of the Election Center in the Academy for State and Iocal Government clearly fulfills a need. Its efforts should be expanded.

\section{Implementation of an Internal Control Function} Essential recommendations are that the concept of internal control should be extended so as to be applicable to vote-tallying, and that persons knowledgeable in that professional field should be utilized to assist in the establishment and implementation of sound operational procedures. To the extent that computerized voting equipment and software must have supporting capabilities, these procedures should be reflected in procurement specifications.

Internal control, which is nearly universally used as a management technique in financially oriented applications (e.g., in banking or manufacturing, or to safeguard assets in any type of organization), has not been applied to vote-tallying because those operations are not priced. Applicability of internal control to votetallying requires only the redefinition of the concept of a transaction. A transaction is now defined as a business event that is measured in money and that is en- 
tered into accounting records; the redefinition would allow a transaction to include a step in the implementation of an entitlement that is not measured in money.

Expertise in internal control (which includes computer security) should be added to the personnel complement in election administration in order to assure implementation of its concepts. In addition, an internal auditor should be available to independently review the implementation of internal controls and report on their effectiveness. Internal control is a professional activity; trained persons, texts, and a community of practitioners are available. Internal control expertise may be shared among government agencies if individual agency resources are insufficient. prior to final acceptance. Qualification implies conformance with standards and functional requirements. and may be done once to satisfy many states. Certification ensures that the product meets state requirements. Acceptance testing evaluates the degree to which the specific units delivered to the local government conform to approved characteristics.

\section{Revised Texas Statute on Electronic Voting Systems} The requirements of the revised Texas statute on electronic voting systems should be considered for adoption in those states that have not already adopted equivalent or more stringent provisions. Requirements of the Texas statute include audit trails, deposit of computer

"Extra votes may be entered in the form of bogus ballots on punch cards, or vote totals may be altered through the use of control cards," said (Howard) Strauss (associate director of the Princeton Computer Center). "Either of these assaults on the system could be performed successfully by a computer novice."

An important function of internal control is to identify system vulnerabilities and convert them into a set of realistic threats. Responses must be devised that are consistent with available or obtainable resources, based on a risk analysis determining the likelihood and cost of actual exploitation of a particular vulnerability. As a result, internal controls personnel should be able to provide assurances to the public that the potential threats are understood, have been prioritized for significance, and are being countered.

The availability of internal control specialists should relieve election administrators from having to be personally knowledgeable about specific technical matters best left to individuals who are professionally qualified in that field. With the addition of needed technical resources to the staff, election administrators would be able to retain management control, and not have to abdicate it to others, such as vendors or data processing center directors. Thus, election administrators would be able to retain the capability of directing that the objective of assuring accuracy, integrity, and security in. vote-tallying be carried out.

\section{FEC Clearinghouse Specifications}

The performance specifications developed by the National Clearinghouse on Election Administration of the Federal Election Commission (FEC Clearinghouse) are approaching completion, and they are intended for statewide adoption. Each state should consider the adoption of thesc specifications when they are issued.

Acceptance procedures for hardware and software should be consistent with the FEC Clearinghouse implementation plan for adoption of these specifications. That plan calls for qualification and certification programs with the secretary of state, assurance that programs used in vote-tallying are identical to those deposited, mandatory one percent manual recount of all contests, testing of equipment using all applicable ballot formats, disconnect of remote terminals during vote tabulations, and specific scrutiny of ballot count discrepancies.

\section{HARDWARE RECOMMENDATIONS}

The value of a ballot-tallying system is that it should be possible, with a recount, to duplicate the result of an election. The problems found in ballot-reader inaccuracy, both in the count of ballots, and in the count of votes on ballots, are a significant source of lack of confidence in vote-tallying.

A recommended goal is that a computerized vote count should be able to be reproduced on a recount with no more than a change in one vote for each ballot position in ballot quantities of up to 100,000 when machine-generated (ideal) ballots are used. $A$ ballot reader should be able to tolerate a wide range of punching or marking behavior by a voter without a significant increase in error.

The use of pre-scored punch cards contributes to the inaccuracy and to the lack of confidence. It is generally not possible to exactly duplicate a count obtained on pre-scored punch cards, given the inherent physical characteristics of these ballots and the variability in the ballot-punching performance of real voters.

It is recommended that the use of pre-scored punch card ballots be ended. One method now available to eliminate pre-scored cards, while retaining the "votomatic" concept, is with a new type of hole-punching stylus that uses spring-loading. A hole of corssistent 
and acceptable dimensions can be created by a voter using the new stylus without the need for pre-scoring. The internal construction of the "votomatic" ballot holder must be altered with the use of the new stylus. Other devices and methods for elimination of prescored punch card ballots also may be effective.

If a ballot cannot be read by machine, administrative controls should be in place to permit such ballots to be counted manually. A voter's choices should not be lost because of machine failure.

Testing to determine the accuracy of current ballot reading systems (such as that now being carried out by ECRI of Plymouth Meeting, PA), and research to improve ballot tallying systems in accuracy and ease of voter use, are important to pursue.

Design of Direct Recording Electronic (DRE) Machines With DRE machines, no ballot is used. The voter enters choices directly into a storage unit of the machine with the use of pushbuttons, a touch screen, or similar devices. As no voter-generated records of choices exist, and no recount independent of the machine is possible, steps should be taken in the design of these machines to assure complete confidence in the reported results.

A problem with most DRE machines as currently designed (as with lever machines, their predecessors), is that there is no difference in the results seen between a voter's failure to cast a vote and the machine's failure to record a vote. mation of the voters' choices that it recorded. The correctness of the machine's data entry process cannot be checked in this manner.

DRE data entry hardware should be certified for logical correctness, by examination of the logic design and by testing under a large variety of different conditions. The DRE data entry function must be correct, as there are no ballots to provide an independent check. The data entry logic and its documentation should be deposited with the state.

(Software recommendations are discussed in the accompanying box "Vulnerabilities of Vote-Tallying Software" beginning on p. 1190.)

\section{RECOMMENDATIONS ON OPERATIONAL PROCEDURES}

Lack of sufficient pre-election testing appears to be a major source of operational difficulty. Sufficient preelection testing should be done so that errors in software specialization or in implementation of logical rules, if any, will become obvious. It is recommended that to the greatest extent possible, all hardware and software to be utilized should be given a dry run simulating specific conditions to be faced on election day and election night.

Audit Trails. Audit trails provide the supporting documentation through which the correctness of the reported results may be verified. Two types of audit trails

\section{"Many local election officials are baffled by computers and are unable to understand, question and challenge the computer systems."}

Recording of Undervotes. It is recommended that each DRE machine be designed so as to take a positive action indicating a "no vote" for every choice that the voter fails to take. When voting is complete, the voter's choices, and any "no votes" for votes not taken, would be transferred to a more permanent storage for summation with other voters' choices. The required transfer and summation of the "no votes" would serve as positive indications of the voter's failure to make certain specific choices. Thus, there would be no ambiguity about whether the voter failed to vote or the machine failed to record selections.

Retention of Voter-Choice Sets for Summation Verification. Each voter-choice set (i.e., the machine's record of all choices of a voter) should be retained in the machine on a removable non-volatile medium (e.g., magnetic disk). Storage locations of the voter-choice sets would have to be randomized to prevent association of a particular set with a particular voter. The retention of the voter-choice sets makes possible a verification (on an independent machine) of the DRE machine's sum- are necessary to document operations and provide confidence in the results reported. One type records steps in the operation of the equipment, while the other records steps in the voting and vote-tallying processes. Complete Data from Split Precincts. Each split of a split precinct should be treated like a separate precinct for the reporting of ballots and votes cast.

Access Controls. Access (i.e., security) controls must be in place during preparations for voting, voting itself, and vote-tallying. These controls concern access to sites, areas, facilities, equipment, documents, files, and data. The controls cover transportation of ballots and telecommunication of results.

Internal Controls for Tallying Systems. These controls should be in place to prevent all types of ballot frauds and miscounting errors, and to provide the documentation and assurance that the correct results are reported. The controls on ballots cover printing and distribution, accounting for use, validity, and prevention of errors 


\section{VULNERABILITIES OF VOTE-TALLYING SOFTWARE}

Software that is intended for use in more than one election is usually written in a generalized form, and then specialized for a specific election. The generalized software may be provided with a set of tables whose values are to be filled in during specialization.

This two-step process may be applied to any form of computerized system: punch card, mark-sense, or DRE (Direct Recording Electronic) machine. The specialization process establishes the number and names of offices and issues to be considered by the voters; the number of candidates and their names for each office; the number of allowable votes for multiple selection situations; and the implementation of special voting rules, such as for treatment of straight-party overvotes and for crossover voting. When the implementation for which the software is being provided includes precinctlocated machines, the specialization process includes provision of the necessary parameters to complete the tables in the software of those machines. A device may be provided that can be used to copy the parameters of the election for each precinct from the main computer into the EPROM of the appropriate precinct-located machine.

Software vulnerabilities include logical errors, the possibility of hidden code, and undocumented changes. No system type is immune from these threats. Protecting the software requires implementation of effective management procedures that assure system integrity and security.

Logical errors. There are several categories of logical errors to be considered. First, a distinction may be made between generic logical errors that are independent of the conditions of elections, and election-related errors. Then, the latter may be subdivided into rule-implementation errors and setupconclition errors. Rule-implementation errors concern preestablished voting rules, such as for crossover voting and for straight-party overvotes. Setup-condition errors involve specific election matters, such as wrong rotations and incorrect assignments of candidates to districts.

Generic logical errors should be identified and eliminated during acceptance testing, when the software is first procured for use. (Acceptance at the state level, involving approval for subsequent use within the state, may constitute a certification.) Ideally, certification/acceptance activity should include a test of all possible features and functions and combinations. Resource constraints may limit testing to only some of the possible combinations of program features for a system. Certification/acceptance testing may involve review of logical flow charts and specific program code, as well as determination of system response to the normal flow of ballot data. Additionally, responses may be evaluated against the input of incorrect data, special cases, large volumes of data, and unplanned hardware failures while processing. Guidance in planning computer software acceptance testing is available [5], [10].

Certification/acceptance testing requires evaluation of the software as it will be implemented, so that elimination of ruleimplementation errors should be a byproduct of this activity. A particularly difficult type of rule to implement is the required restriction in some states to one vote per candidate per voter in a vote-for-two situation when a candidate is tisted on two party lines for the same office. Should a voter attempt to vote for the same candidate on both party lines in this situation, an incorrectly implemented DRE, punch card, or marksense system may assign the candidate two votes.
Elimination of setup-condition errors is necessary as an activity in pre-election system checkout. In precinct-count systems, it is important to verify that the computer is implemented for the same rotation and other setup conditions as seen on the ballot for that precinct. in central-count systems, testing the system against a large number of ballots or ballot images may bring to light the presence of setup-condition errors. In any system in which there is ballot rotation, it is important to assure that the summarization of each candidate's votes is correct, considering the different ballot position of the candidate in the various precincts.

Hidden code. This term refers to a secret computer program inserted into another program provided to an unaware user. The purpose of the hidden code may be malicious, or it may be used to demonstrate the capability of the perpetrator, or it may be used to surreptitiously record information for later retrieval. The effort of finding any hidden code within a votetallying program may be assisted with the use of a software engineering tool that identifies the use of each path in the program during program execution. If, in the exercise of a vote-tallying program, a particular path is not used (because the conditions that select it have not been employed), such a path may be further investigated to determine the selection conditions.

The problem of finding hidden code is complicated when vote-tallying software is mounted on a general-purpose computer. Hidden code may have been initially placed in a support program of the computer, for example the compiler or operating system. Such hidden code may be activated when the support program is called from the vote-tallying program. If a clock could be accessed by the hidden code, activation could be arranged to occur at a particular time on a particular day. The identification of the presence of such hidden code could be difficult and time-consuming, and a deliberate search, without specific evidence that the code exists, could be impractical.

Assuring System Integrity. Realistic protection against the presence of hidden code in a general-purpose computer installation involves the application of general administrative controls over the installation. An important admiristrative control for protection against hidden code is the requirement that software be supplied only from an original manufacturer who is known, reliable, and can be held accountable. The copying of software from secondary sources should be forbidden.

Modifications to software must be strictly controlled to prevent unauthorized changes. Restrictions must be in place to control access to program codes that have been approved for operation. Authorized changes should be documented. Previous versions of revised software should be retained according to established procedures. Due to the threats from hidden code, computer programs have been written that protect against it. The protective program is intended to run with an application, and to identify any modifications that are made. However, it is necessary that the application be initially free of any hidden code because only subsequent changes can be identified. In addition, the protective program could not prevent the unauthorized modification of itself that might be undertaken from outside the program, tor example from the operating system:

An additional strategy to protect system integrity is to have the vote-tallying software provided by its divveloper 
with all necessary support software, including the operating system, as a complete package. No other software would be necessary. In this way, the complete software for votetallying is separated from the influences of all other software. It is common practice for software for precinct-located machines to be provided in this condition. in the future, states may require the complete package of software (for any type of vote-tallying system) to be deposited with the chief elections official or an escrow agent, so that the provision of a complete package of software is responsive to this anticipated request.

The provision of a complete software package enables an additional protection to be applied: the data authentication code (DAC) [3]. This code value, a binary number, is computed by first randomly selecting a certain key value, and then applying that key and a specific mathematical function to the software package. The key value is kept secret. The computation of the DAC (which contains the same number of bits as the key) protects the software against both accidental and intentional unauthorized data modification. To apply the function, the software package is treated as if it were a digitally-encoded message, as the DAC was developed to authenticate messages transmitted over communication lines. In application, the DAC would be generated for the original software deposited with the state, and would be generated also for the supposedly identical software used in an election. The two values of the DAC will be identical if the software packages are identical. (The software to be used in an election would have to be compared with the master copy before subsequent specialization for the election.)

due to mishandling. The controls on data and calculations provide for accurate telecommunication of data, recording of undervotes and overvotes, vote reconciliations that demonstrate consistency, and assurance of accurate vote summarization. A manual recount of at least one percent of the ballots of each contest is recommended. Responsibility for selection of some of the precincts to be recounted should be granted to candidates or parties.
There is a very small possibility that other software packages will have the same DAC value. If the software were altered, the probability of the DAC being the same for the altered software is extremely small. in fact, the probability is inversely proportional to the binary power of the number of bits in the DAC. That is, with an increase of one bit of length in the DAC, the probability of identicality is halved. Typical lengths of the DAC are from 32 to 64 bits. Furthermore, altered software could not be designed to have the same $\mathrm{DAC}$ value unless the persons performing the alteration knew the secret key used to create the DAC.

Assuring System Security. Provision of all software as a complete package implies that the computer on which the software is to run can be dedicated to election operations. With the wide availability and downward cost trend of minicomputers and microcomputers, this possibility is reasonable, even for smaller election administrations.

The advantage of a dedicated computer is that access to the computer installation may be restricted by the election administration. Controlled access implies restrictions on electronic access to files through terminals or modems as well as restrictions on personnel entry. Sources of hardware, software, and supplies that are used may be controlled to assure accountability. When the election administration simply serves as one of many users of a general-purpose installation, such restrictions enforced by the election administration are not generally available. The election administration may not be able to assure that the special concern for security necessary in election operations has the same or higher priority in the general-purpose installation.

revealed the need for improvements in hardware and software performance and in operational procedures, and they have provided support for the need for institutional changes. Thus, the reviews have influenced the recommendations provided in this report.

Specific recommendations directly resulting from the reviews of difficulties include the recommendations on improved accuracy in ballot tabulation, elimination of pre-scored punch card ballots, assurance of the count-

\section{"Election system vendors are often forced by competitive bidding pressures to offer jurisdictions the cheapest possible systems, and the products they offer do not maximize fraud protection."}

Internal Controls for DRE Systems. These controls should be in place to provide documentation and assurance that the correct results are reported when DRE systems are used. The controls cover matching machine use with voter totals, vote reconciliations on each machine, recounting of voter-choice sets, and post-election checkout of machines.

\section{FUTURE SYSTEMS}

Although none of the computer difficulty situations (reviewed in this report) has provided solid evidence of computer program manipulation, the reviews have ing of ballots rejected by readers, provision of complete data from split prerincts, and more thoroughness in pre-election checkout.

While vote-tallying using telephones or stations similar to automatic teller machines is technologically feasible, the decision to implement such a system must be based on more fundamental factors. Any installed system must meet political and economic requirements, as well as technical requirements of accuracy and reliability. Political needs include equal access by individuals, 
9. Furnas, G.W. Experience with an adaptive indexing scheme. In Proceedings of the ACM SIGCHI Conference on Human Factors in Computing Systems, (San Francisco, Calif., Apr. 14-18, 1985). ACM. New York, 1985, pp. 131-135.

10. Gordon, Michael D. Evaluating the effectiveness of information retrieval systems using simulated queries. J. Amer. Soc. Inf. Sci. To appear.

11. Harter. S.P. A probabilistic approach to automatic keyword indexing. Part 1: On the distribution of specialty words in a technical literature. J. Amer. Soc. Inf. Sci. 26, 4 (July-Aug. 1975), 197-206. Pcrt 2: An algorithm for probabilistic indexing. J. Amer. Soc. Inf. Sci. 26.5 (Sept.-Oct. 1975), 280-289

12. Holland, I. Adaptation in Natural and Artificial Systems. University of Michigan Press, Ann Arbor, Mich., 1975.

13. Holland, J. H. Escaping brittleness: The possibilities of generalpurpose learning algorithms applied to parallel rule-based systems. In Machine Learning Vol. 2, R.S. Michalski, J.G. Carbonell, and T.M. Mitchell, Eds. Morgan Kaufman, Los Altos, Calif., 1986.

14. Maron, M.E., and Kuhns. J.L. On relevance, probabilistic indexing, and information retrieval. J. ACM 7, 3 [1960], 216-244.

15. Robertson, S.E., and Sparck Jones, K. Relevance weighting of search terms. I. Amer. Soc. Inf. Sci. 27, 3 (May-June 1976), 129-146.

16. Robertson, S.E., Maron, M.E., and Cooper, W.S. Probability of relevance: a unification of two competing models for document reIrieval. Inf. Tech.: Res. Dev. 1, 1 (Jan. 1982), 1-21.

17. Salton, G., Yang, C.S., and Yu, C.T. A theory of term importance in automatic text analysis. J. Amer. Soc. Inf. Sci. 26, 1 (1975), 33-44.

18. Tague, J., McClellan, C., and Nelson, M. The hyperterm model of a bibliographic database. Can. I. Inf. Sci. 9 (June 1984), 37-58.

19. Van Rijsbergen, C.J. Information Retrieval, 2d. ed. Butterworths, London, 1979.

20. Van Rijsbergen, C.J. A theoretical basis for the use of co-occurrence data in information retrieval. J. Doc. 33, 2 (1977), 106-119.

21. Zunde, P., and Dexter, M.E. Indexing consistency and quality. Amer. Doc. 20, 3 (July 1969), 259-267.
CR Categories and Subject Descriptors: H.3.1 [Information Storage and Retrieval]: Content Analysis and Indexing-indexing methods; H.3.3 [Information Storage and Retrieval]: Information Search and Retrieval-retrieval models: selection process; I.2.6 [Artificial Intelligence] Learning-concept learning; parameter learning

General Terms: Algorithms, Design, Experimentation, Performance Additional Key Words and Phrases: Adaptive retrieval, document redescription, document retrieval, genetic algorithms, frobabilistic information retrieval

ABOUT THE AUTHOR:

MICHAEL GORDON is an Assistant Professor of Computer and Information Systems at The University of Michigan Graduate School of Business Administration. The focus of his research is information retrieval. He is currently exploring adaptive techniques for retrieving documents as well as methods for storing and retrieving computer models. He has written about information retrieval simulation, information retrieval theory, and the importance of information retrieval for business. Author's present address: Michael Gordon, Graduate School of Business Administration, University of Michigan, Ann Arbor, MI 48109. Electronic address: Michael_Gordon@ub.cc.umich.edu

Permission to copy without fee all or part of this material is granted provided that the copies are not made or distributed for direct commercial advantage, the ACM copyright notice and the title of the publication and its date appear, and notice is given that copying is by permission of the Association for Computing Machinery. To copy otherwise, or to republish, requires a fee and/or specific permission.
Saltman (continued from $p .1191$ )

the ability to verify registration, and the ability of the voters to vote in secret without intimidation. Internal controls must be implementable to demonstrate the correctness of the reported results. Benefits, such as increased voter convenience and possible improved participation rates must be compared against the costs of implementation.

\section{REFERENCES}

1. Audit of Recount Detects Error, Restores Stark County, Ohio Commissioner Victor. Election Administration Reports 16, 5 (July 21, 1986), $2-4$

2. Burnham, D. "Computerized systems for voting seen as vulnerable to tampering." The New York Times (July 29, 1985), 1.

3. Computer Data Authentication. Federal Information Processing Standards Publication 113, National Bureau of Standards, May 30, 1985.

4. Guy, C. "Election system under fire nationwide." Carroll County Times (July 11, 1985), 1

5. Hetzel, W. The Complete Guide to Software Testing. QED Information Sciences, Wellesley, MA 1984.

6. Kelly, S. "Human error reversed school board election results." Carroll Sun (November 18, 1984), 2

7. Lewis, T.W., Ensor, T.E., and Gosnell, J.S. "Certain factors which involved the Carroll County Board of Election Supervisors, Either Directly or Indirectly, in Producing the Numerical Results of the General Election in Carroll County, November 6th. 1984." (Decem. ber 4,1984 ).

8. Saltman, R.G. Effective Use of Computing Technology in Vote-Tallying National Bureau of Standards, NBSIR 75-687, March, 1985. 13. "Recounting," 91

9. Van de Bussche, T.J. Letter to Dr. Thomas Lewis, November 26, 1984
10. Wallace, D.R. An Overview of Computer Software Acceptance Testing. National Bureau of Standards Special Publication 500-136. (February, 1986)

CR Categories and Subject Descriptors: J.1 [Administrative Data Processing]: General; K.4.2 [Computers and Society]: Social Abuse; K.6.4 [Management of Computing and Information Systems]: System Management; K.6.m: [Miscellaneous]: Security.

Additional Key Words and Phrases: Accuracy, computer election, integrity, internal control, security, vote tallying

ABOUT THE AUTHOR:

ROY G. SALTMAN is a computer scientist at the Institute for Computer Sciences and Technology of the Naticnal Bureau of Standards. His current research interests include the use of computers for vote-tallying as well as the adoption of electronic data interchange (EDI) for use in the Federal Government. The complete title of his report from which this article is based is Accuracy, Integrity and Security in Computerized VoteTallying, National Bureau of Standards Special Publication Number 500-158, August, 1988. Author's present address: Roy G. Saltman, Institute for Computer Sciences and Technology, National Bureau of Standards, Gaithersburg, M[I 20899.

Permission to copy without fee all or part of this material is granted provided that the copies are not made or distributed for direct commercial advantage, the ACM copyright notice and the title of the publication and its date appear, and notice is given that copying is by permission of the Association for Computing Machinery. To copy otherwise, or to republish, requires a fee and/or specific permission. 